\title{
Estudio del estado de nutrición y los hábitos alimentarios de comunidades otomíes en el Valle del Mezquital de México*
}

\author{
Richmond K Anderson, MD, José Calvo, MD, Gloria Serrano, MD, George C Payne, MD
}

\begin{abstract}
Resumen
Se presentan los resultados de un estudio nutriológico en grupos de indígenas otomíes delValle del Mezquital de México. La región es árida, estéril y económica y culturalmente una de las más deprimidas del país. Los habitantes comían muy pocos de los alimentos considerados comúnmente como esenciales para lograr una buena nutrición. Su consumo de carne, leche y sus derivados, frutas y verduras es extremadamente bajo. Sin embargo, por el consumo de tortillas, pulque y todas las plantas disponibles que se pueden considerar comestibles, se logra una dieta suficientemente adecuada.
\end{abstract}

$\mathrm{E}$ 1 presente trabajo es el informe de un estudio sobre nutrición llevado a cabo en cuatro comunidades indígenas en el Valle del Mezquital de México. Dos de ellas fueron estudiadas de octubre a diciembre de 1943 y las otras de marzo a septiembre de 1944.

El Valle del Mezquital se encuentra en un área que atraviesa la carretera panamericana y que se sitúa entre 97 y 193 km al norte de la Ciudad de México. Las cuatro comunidades estudiadas se ubican en el extremo sur del Valle, a unos $120 \mathrm{~km}$ de la capital del país. Los habitantes son predominantemente indígenas, aunque puede apreciarse cierto mestizaje.

La mayoría de los historiadores opina que los indios otomíes fueron originalmente habitantes del Valle de México, pero que fueron desplazados hacia los alrededores por invasiones sucesivas que terminaron con la de los aztecas. En lo fundamental ellos continúan practicando sus costumbres nativas, no obstante la influencia española que data de la primera mitad del siglo XVI.

EI principal idioma era el otomí, sin embargo en las dos primeras comunidades, que se encuentran cerca de un pueblo de alrededor de 3500 habitantes, casi toda la población hablaba también el español. En las otras dos localidades, en cambio, un alto porcentaje de la población hablaba solamente otomí y sus habitantes eran más ignorantes y desconfiados y menos cooperadores.

La región se encuentra a una altura de 2000 metros sobre el nivel del mar y su clima es templado (la temperatura promedio de 1921 a 1935 fue de $16.3^{\circ} \mathrm{C}$, con máxima de $34.5^{\circ}$ y mínima de $5.5^{\circ}$ ). La región es extremadamente árida e inadecuada para la agricultura de temporal. Algunas áreas del Valle cuentan con sistemas de riego, en cambio las comunidades estudiadas no disponen de estos. El promedio de la precipitación

\footnotetext{
* Los estudios y observaciones en los que se basa este informe fueron conducidos bajo los auspicios y con el apoyo de The International Health Division of the Rockefeller Foundation en cooperación con la Secretaría de Salubridad y Asistencia de México y sus dependencias: Instituto Nacional de Nutriología, Escuela de Higiene y el Centro de Adiestramiento de la Escuela de Higiene.

Publicado originalmente en American Journal of Public Health:Anderson RK, Calvo J, Serrano G, Payne GC. A study of the nutritional status and food habits of Otomi Indians in the MezquitalValley of Mexico.Am J Public Health 1946;36:883-903. Se reproduce con autorización de la American Public Health Association (APHA), quien mantiene la posesión de los derechos de autor. La APHA no se hace responsable por la precisión de la traducción al español del presente artículo.
} 
pluvial anual para el periodo de 1921 a 1935 fue de 440 $\mathrm{mm}$, con promedio de 52 días con precipitación mayor a $0.1 \mathrm{~mm}$. Rara vez se obtienen cosechas satisfactorias; sin embargo, la agricultura continúa siendo una de las principales ocupaciones de los habitantes del área.

Antes de la situación actual de la tenencia de la tierra existían grandes ranchos dedicados a la producción de pulque por la falta de riego. El pulque es una bebida obtenida de la fermentación del aguamiel, que a su vez proviene del maguey. Cuando las grandes propiedades fueron repartidas, muchas familias adquirieron pequeñas parcelas en las que iniciaron el cultivo de algunos alimentos, principalmente el maíz y el frijol; sin embargo, la producción de estos cultivos es generalmente muy baja. Al parecer la producción del pulque ha ido disminuyendo, ya que se adapta mejor a la producción en gran escala; aun si continua siendo importante para la economía y nutrición de la gente de la región. Otra ocupación habitual de los habitantes es el tejido de la fibra de maguey (agave).

En las dos primeras comunidades se fabricaban con el agave tapetes rústicos, en las otras paños ásperos de forma cuadrangular llamados ayates, los cuales se utilizan fundamentalmente para cargar objetos.

La gente vive en pequeñas chozas construidas con hojas de maguey, las cuales se acomodan sobre armazones rústicos hechos con varas largas. Dichas chozas resultan muy permeables a los elementos naturales, incluyendo la lluvia. Una pequeña parte de la población habita viviendas de adobe o piedra. Los techos de la habitación se elevan tan poco del suelo, que comúnmente se encuentran ocultos por arbustos o cactus; además, por su gran dispersión frecuentemente se dificulta su localización. Uno puede encontrarse en el centro de un poblado y considerarse en una región deshabitada.

Su ropa es pobre e insuficiente, y la mayoría de la gente viste un mismo conjunto de prendas que no se lava con frecuencia y se utiliza hasta su deterioro. La ropa usada por los padres pasa comúnmente a ser utilizada por los hijos. La mala higiene personal de la gente puede ser atribuida en mucho a las condiciones económicas y la escasez de agua. Cada comunidad cuenta con uno o dos pozos, generalmente muy profundos, de los que los habitantes obtienen el agua y la transportan a sus casas, lo que requiere de mucho trabajo.

La infestación con piojos es prácticamente universal, encontrándose en las dos primeras comunidades una infestación de 90 y 85\% respectivamente; la situación es probablemente similar en las otras dos. El tifo es endémico en la región; no obstante, no se encontraron casos en estas comunidades en el momento del estudio.

Se realizó un registro de los ingresos y los gastos destinados a alimentación de todas las familias. El 25\% de estos registros fueron analizados, encontrándose un gasto para alimentos de sólo 6.68 pesos por semana y por familia (equivalente a 1.38 dólares) y 1.64 pesos ( 0.34 de dólar) por persona semanalmente. Este promedio se basa en el valor encontrado en el mercado de casi todos los alimentos adquiridos, con excepción de parte del pulque y varias plantas silvestres consumidas, a las cuales no se les puede asignar valor monetario. El pulque es habitualmente producido por algunos individuos y vendido al resto de la comunidad; sin embargo, muchas familias tienen algunos magueyes y producen cantidades pequeñas de la bebida para el autoconsumo. Debe señalarse que los precios de los alimentos eran muy altos al momento del estudio. El precio del maíz, el principal alimento consumido, era de 50 centavos el $\mathrm{kg}$ en el mercado local. Un promedio de $75 \%$ del ingreso total se destinaba a la alimentación. Es asombroso que la gente pudiera subsistir en estas condiciones.

Prácticamente no existen instalaciones sanitarias y la atención médica es insuficiente. El agua de los pozos no es potable, lo que probablemente influye en el elevado consumo de pulque. Debido al clima seco y templado de la región, muchas de las llamadas enfermedades tropicales, comunes en otras zonas de México, no existen aquí. Las principales causas de muerte de acuerdo con los registros del Departamento de Salud son: en primer lugar, enfermedades pulmonares, particularmente neumonías, y en segundo lugar, enfermedades intestinales (diarrea, enteritis y disentería). Tanto la tasa de natalidad (aproximadamente 55 por 1000 ), como la de mortalidad general (aproximadamente 31 por 1000 ) y la de mortalidad infantil son muy altas.

Las elevadas tasas de natalidad y mortalidad en niños y adultos jóvenes pueden apreciarse en los datos sobre el número de niños vivos y muertos en las historias clínicas de las mujeres de las comunidades estudiadas.

Las mujeres de entre 35 y 40 años de edad tenían un promedio de seis a siete hijos, de los cuales, alrededor de $40 \%$ estaban muertos. Cerca de $60 \%$ de los hijos de mujeres de 50 años y más habían fallecido.

Es obvio que la región es económica y culturalmente muy atrasada, considerada como una de las más o tal vez la mas atrasada del país. No hemos visto ninguna otra región tan pobre a lo largo de varios viajes extensos por México.

\section{Metodología}

Hasta donde fue posible, la población total de cada comunidad fue examinada. La gente cooperó con el estudio una vez que fue ganada su confianza. Cada individuo fue objeto de un examen físico y una historia 
clínica, prestando especial atención a los posibles signos y síntomas de enfermedad por deficiencia. La córnea, conjuntiva, encías y lengua fueron examinadas con la ayuda de una lámpara de exploración y al microscopio. Cerca del final del estudio un dentista especializado en salud pública examinó las bocas de todas las personas que aceptaron participar en cada comunidad.

El cuadro 1 muestra los resultados del censo y el porcentaje de personas y familias examinadas. El grupo que fue objeto de examen dental especial es relativamente pequeño dado que el dentista trabajó muy poco tiempo en cada comunidad. El número exacto de habitantes de la comunidad es difícil de obtener, por la dificultad para encontrar algunos de los casos y por la actitud recelosa de muchas personas de las comunidades; no obstante, debido al prolongado periodo de resistencia de los investigadores en la región, fue posible obtener un censo exacto de las comunidades estudiadas.

Se realizó una encuesta de alimentos a nivel familiar e individual. Cada familia fue visitada diariamente durante una semana, habitualmente a la hora en que la comida principal había sido preparada. Se tomaba nota de los platillos consumidos y sus ingredientes. Casi ningún alimento se preparaba a horas distintas a la de la comida principal. Por el método de pesas y medidas se determinaron los pesos y volúmenes de los alimentos. Se llevó a cabo un registro del consumo de alimentos por cada miembro de la familia, con base en medidas caseras o porciones de las preparaciones consumidas por cada individuo de la familia; asimismo, se llevó a cabo el registro de alimentos fuera del hogar. Durante el primer día de visita se realizó un inventario de los alimentos presentes en el hogar, manteniéndose un registro de los alimentos comprados o adquiridos de alguna otra manera; también se midieron los desperdicios. Al final de la semana se obtuvo un inventario de los alimentos no consumidos. Los inventarios y el registro de adquisiciones fueron comparados con los registros individuales de consumo de todos los miembros de la familia, con objeto de detectar cualquier error o discrepancia importante.
Los registros generalmente correspondieron a siete días consecutivos, no siendo así en todos los casos; sin embargo, en aquellos que se registraron menos de siete días, se incluyeron un domingo y un día de mercado (los días de mayores cambios en el consumo de alimentos). No se observaron diferencias significativas entre estos dos tipos de registros de dietas.

De los registros semanales de consumo de alimentos a nivel individual, se calcularon los consumos diarios promedio de calorías, proteínas animales y totales, carbohidratos, grasa, vitamina A, tiamina, riboflavina, niacina, acido ascórbico, calcio, fósforo y hierro. No se consideró necesaria ninguna corrección por pérdidas durante la preparación de los alimentos. El valor nutritivo de las tortillas fue obtenido del análisis de dicho alimento tal y como era preparado para su consumo. La mayor fuente de vitamina $C$ era el pulque, el cual se bebía, como es obvio, sin cocinarse. Los chiles seco y verde eran casi siempre molidos y comidos sin cocinar. $\mathrm{Al}$ parecer, los vegetales silvestres eran los únicos alimentos en los que las pérdidas por la preparación podrían ser de mucha importancia, y estos no eran habitualmente cocinados en exceso.

Las tablas utilizadas en el cálculo dietético se basan, fundamentalmente, en el análisis de alimentos obtenidos en México durante el presente estudio; algunos de ellos provenían de la región estudiada. Sólo fue posible analizar algunas muestras de cada alimento (frecuentemente sólo una), por lo que somos conscientes de que los cálculos derivados de dichos análisis pueden ser inexactos; sin embargo, pensamos que los errores son menores que si los cálculos hubieran sido basados en datos de otros países.

Se obtuvieron muestras de sangre aproximadamente de $90 \%$ de las personas sometidas a examen físico y fueron excluidos los niños pequeños menores de dos años. De aproximadamente $20 \mathrm{ml}$ de sangre obtenida de cada individuo, alrededor de $4 \mathrm{ml}$ fueron oxalatados con una mezcla de potasio seco y oxalato de amonio ${ }^{2}$ y utilizados para las determinaciones hematológicas,

Cuadro I

Censos de las comunidades y Proporciones examinadas

\begin{tabular}{|c|c|c|c|c|c|c|c|c|}
\hline \multirow[b]{2}{*}{ Comunidad } & \multirow[b]{2}{*}{$\begin{array}{l}\text { Número de } \\
\text { habitantes }\end{array}$} & \multicolumn{2}{|c|}{ Personas examinadas } & \multirow[b]{2}{*}{$\begin{array}{l}\text { Número } \\
\text { de familia }\end{array}$} & \multicolumn{2}{|c|}{$\begin{array}{c}\text { Familias completamente } \\
\text { examinadas }\end{array}$} & \multicolumn{2}{|c|}{$\begin{array}{c}\text { Personas examinadas } \\
\text { por el dentista }\end{array}$} \\
\hline & & Número & Porcentaje & & Número & Porcentaje & Número & Porcentaje \\
\hline Bothi Baji & 197 & 178 & 90 & 38 & 26 & 68 & III & 56 \\
\hline Las Palomas & 98 & 86 & 88 & 20 & 13 & 65 & 57 & 58 \\
\hline Boxaxni & 585 & 499 & 85 & 116 & 81 & 70 & 270 & 46 \\
\hline Santa Mónica & 269 & 203 & 75 & 52 & 25 & 48 & 154 & 57 \\
\hline Total & 1149 & 966 & 84 & 226 & 145 & 64 & 592 & 52 \\
\hline
\end{tabular}


incluyendo hemoglobina, ${ }^{3}$ hematocrito ${ }^{2}$ y recuento de glóbulos rojos. La sangre restante se empleó para determinar las proteínas séricas totales y albumina por el método cuantitativo de Biuret, ${ }^{4}$ caroteno y vitamina A, séricos ${ }^{5}$ y ácido ascórbico. ${ }^{6}$ En niños menores de 5 años la fosfatasa fue también determinada. ${ }^{7}$ Un frotis de sangre para la detección de paludismo (de ambos tipos: grueso y delgado) fue practicado en la mayoría; también se realizó examen de excremento cuando parecía indicado. Inmediatamente después de obtenidas las muestras de sangre se introducían en un jarro con hielo y ese mismo día eran transportadas por automóvil a la Ciudad de México. Al investigar la estabilidad de los componentes de la sangre bajo esta técnica de manejo, encontramos que no había ningún cambio.

\section{Hábitos de alimentación}

Como en otras partes de México, los alimentos básicos aquí son el maíz (casi invariablemente: tortillas), el frijol y el chile. Los alimentos suplementarios son aquellos disponibles localmente, el mas importante de los cuales es el pulque. La carne se come en muy pequeñas cantidades y es usualmente de borrego o cabra, ya que estos animales son los que mejor se adaptan a las condiciones de esta región. Frecuentemente, la sangre de los animales es consumida y la carne se vende para adquirir alimentos más baratos. Esto mismo sucede con la producción de pequeñas cantidades de leche, huevo y carne de aves. El único animal silvestre que suele consumirse es el conejo. Los frijoles son relativamente caros y se consumen en cantidades menores que en otras partes de México. El consumo de chile es elevado. Pequeñas cantidades de cebolla, ajo, tomate y más raras veces jitomate se utilizan como saborizantes en las preparaciones. La grasa más comúnmente usada para cocinar es la manteca de cerdo, aunque en cantidades relativamente bajas.

Se consumen casi todas las plantas que pueden ser concebidas como comestibles; incluyendo muchos de los cactus. Varias de ellas crecen sin ser cultivadas durante la estación lluviosa y la mayoría de la gente las consideraría como plantas no comestibles. Asimismo, consumen una gran variedad de gusanos e insectos. De este modo se logra una dieta muy variada. Algunas de las plantas que la mayoría de la gente considera como "no comestibles" tienen un sorprendente valor nutritivo; por ejemplo, la fértil malva es fuente excepcional de vitaminas A y C, y hierro. Entre otras, de alguna importancia en la dieta, se incluyen la hediondilla, tunas y nopales, flores de maguey (garambullo), yuca, verdolagas, quelites, xocoyoll y flor y hojas de nabo, lengua de vaca y endivia; a excepción de sus frutos, los cactus casi no se consumen. Rara vez consumen otros vegetales fuera de los ya mencionados.

Muchos alimentos de considerable importancia en las dietas de otras regiones de México se emplean con poca frecuencia en esta área, probablemente por algunas razones económicas. Entre estos se incluyen las frutas y las verduras, pan y otros productos de trigo o de grano, arroz, café, azúcar, pastas, lentejas, chícharos, alubias y cacahuates.

La cocina es bastante simple y consiste en la elaboración de tortillas y la preparación de frijoles. Las verduras son conocidas aunque no excesivamente y no se comen en grandes cantidades. La mayor parte de la gente hace dos comidas al día: la de la mañana y la de la noche; esta última, omitida por la mayoría, generalmente consiste en las sobras de la comida principal.

Los niños son alimentados al pecho hasta edades avanzadas, algunas veces durante varios años, y no fue raro encontrar mujeres con varios niños lactando a la vez. El estado común de las mujeres en edad fértil era el embarazo o la lactancia. Las encuestas dietéticas de hijos cuyas historias indicaban que continuaban siendo amamantados en alguna medida fueron excluidas de las tabulaciones.

El pulque es bebido par casi toda la población y frecuentemente en grandes cantidades, en muchas casos sustituye totalmente al agua. Está generalizada la creencia de que dicha bebida es muy nutritiva; muchos hombres afirmaban que no podrían trabajar si no bebían pulque y que servía como sustituto de la carne en la dieta. Aun los bebés y niños pequeños lo consumen considerablemente (cuadro 2).

El pulque es el producto de la fermentación de un líquido producido por el maguey. Ocho o diez años después del trasplante del maguey, un poco antes de que brote el tallo central que sostiene a la flor, se remueve esa parte central dejándose un receptáculo en forma de copa. Dentro de esta copa drena un líquido de las hojas, el cual es removido diariamente con una pipeta hecha de una calabaza alargada. Las caras internas de la copa deben ser raspadas diariamente con objeto de mantener el flujo de líquido. Las hojas almacenan gran cantidad de azúcar (principalmente sacarosa) para cubrir las necesidades energéticas del rápido crecimiento del tallo que sostiene la flor, por lo que el líquido producido es muy dulce y se conoce como aguamiel. Este líquido es inoculado con un cultivo de pulque previamente elaborado y se deja fermentar por un tiempo variable, generalmente alrededor de 10 a 12 días. Después de alcanzar su punto óptimo debe ser tornado en un lapso entre 24 y 48 horas, ya que los microorganismos fermentados no son separados y la fermentación continúa sin freno, causando deterioro en el producto. La presencia del fermento le da 
Cuadro 2

Consumo CALÓRICO

\begin{tabular}{|c|c|c|c|c|c|c|c|c|c|c|c|c|c|}
\hline \multirow[b]{3}{*}{ Número de personas } & \multicolumn{4}{|c|}{ Ambos sexos } & \multicolumn{4}{|c|}{ Sexo masculino } & \multicolumn{4}{|c|}{ Sexo femenino } & \multirow{3}{*}{$\begin{array}{l}\text { Todo el } \\
\text { grupo } \\
856\end{array}$} \\
\hline & \multirow{2}{*}{$\begin{array}{l}1-3 \\
62 \\
\end{array}$} & \multirow{2}{*}{$\begin{array}{l}4-6 \\
102\end{array}$} & \multirow{2}{*}{$\begin{array}{l}7-9 \\
87\end{array}$} & \multirow{2}{*}{$\begin{array}{r}10-12 \\
72\end{array}$} & \multicolumn{2}{|c|}{$13-1516-20$} & \multirow{2}{*}{$\begin{array}{r}21-50 \\
147 \\
\end{array}$} & \multirow{2}{*}{$\begin{array}{r}50+ \\
43 \\
\end{array}$} & \multirow{2}{*}{$\begin{array}{r}13-15 \\
22 \\
\end{array}$} & \multicolumn{2}{|c|}{$16-2021-50$} & \multirow{2}{*}{$\begin{array}{r}50+ \\
53 \\
\end{array}$} & \\
\hline & & & & & 25 & 35 & & & & 39 & 169 & & \\
\hline Media de calorías al día & 952 & 1121 & 1273 & 1518 & 1645 & 2098 & 2454 & 2144 & 1533 & 1818 & $|83|$ & 1614 & 1706 \\
\hline Error estándar de la media & 39 & 36 & 47 & 61 & 100 & 139 & 63 & 126 & 92 & 97 & 45 & 59 & 26 \\
\hline $\begin{array}{l}\text { Consumo recomendado por el } \\
\text { National Research Council }\end{array}$ & 1200 & 1600 & 2000 & 2500 & 3200 & 3800 & 3000 & 3000 & 2600 & 2400 & 2500 & 2500 & 2430 \\
\hline $\begin{array}{l}\text { Porcentaje del consumo reco- } \\
\text { mendado }\end{array}$ & 79 & 70 & 64 & 61 & 51 & 55 & 82 & 71 & 59 & 76 & 73 & 65 & 70 \\
\hline Promedio de cal/24 h dividido & & & & & & & & & & & & & \\
\hline entre calorías basales & 1.59 & 1.84 & 1.28 & 1.30 & 1.29 & 1.45 & 1.69 & 1.58 & 1.22 & 1.50 & 1.51 & I.44 & 1.53 \\
\hline $\begin{array}{l}\text { Porcentaje de calorías que pro- } \\
\text { vienen de carbohidratos }\end{array}$ & 73 & 74 & 73 & 72 & 70 & 68 & 63 & 66 & 71 & 69 & 66 & 67 & 69 \\
\hline $\begin{array}{l}\text { Porcentaje de calorías que pro- } \\
\text { vienen de grasas }\end{array}$ & 12.7 & 11.7 & 11.8 & 12.1 & 11.8 & 10.7 & 10.0 & 9.9 & 11.4 & 11.7 & 10.5 & 10.9 & 11.1 \\
\hline $\begin{array}{l}\text { Porcentaje de calorías } \\
\text { que provienen de proteínas }\end{array}$ & 12.2 & 11.9 & 12.3 & 12.2 & 12.4 & 11.9 & 11.7 & 11.6 & 12.1 & 12.2 & 11.9 & 12.0 & 12.0 \\
\hline $\begin{array}{l}\text { Porcentaje de calorías que } \\
\text { provienen de alcohol del pulque } \\
\text { (todo el grupo) }\end{array}$ & 1.9 & 2.2 & 3.1 & 3.4 & 6.1 & 9.2 & 14.8 & 12.9 & 5.4 & 6.6 & II.I & 8.0 & 10.4 \\
\hline $\begin{array}{l}\text { Porcentaje de calorías que } \\
\text { provienen del alcohol (sólo } \\
\text { bebedores) }\end{array}$ & 3.6 & 3.3 & 4.6 & 5.5 & 8.0 & 10.1 & 15.7 & 13.3 & 6.2 & 8.6 & 11.7 & 10.8 & 9.1 \\
\hline
\end{tabular}

al pulque una apariencia blancuzca y turbia. La bebida es ligeramente ácida y su sabor no es desagradable, pero se produce en condiciones antihigiénicas; sin embargo, su acidez probablemente impide que se convierta en un buen medio de cultivo para organismos patógenos.

Debido a que los microorganismos que causan la fermentación no son removidos, éstos aportan alguna cantidad de vitamina $C$.

El consumo promedio de pulque por los hombres, según nuestros registros de dietas, era de 1 a 2 1itros por día; esta estimación posiblemente sea baja, dada la dificultad de obtener un registro adecuado del consumo de un líquido bebido en forma abundante a cualquier hora. No era raro encontrar hombres que bebían 10 litros al día. El contenido de alcohol del pulque es bajo ( 3 a $5 \%$ ), pero no obstante eso, comúnmente se observaba ebriedad, particularmente los días de mercado y de fiesta.

La importancia relativa del pulque y otros alimentos principalmente puede observarse en el cuadro 3, que es el resultado del análisis de 100 registros de dietas, seleccionadas según el numero de habitantes y distribución de la edad y el sexo en las comunidades de estudio. Los porcentajes se ordenan de acuerdo con las principales fuentes de cada nutrimento. Como puede observarse, las tortillas son por mucho el alimento más importante por sí solo, seguidas del pulque. Esto no significa que el pulque tenga un elevado valor nutritivo o que sea especialmente recomendado como fuente de cualquiera de estos nutrimentos; sin embargo, debido al carácter marginal en la dieta del resto de los alimentos, este adquiere importancia, especialmente por su aporte de vitamina $C$.

\section{Resultados}

Los cuadros sobre dietas muestran los consumos de alimentos para edades y sexos y establecen una comparación can los de recomendaciones de consumo de alimentos del National Research Council.*

* Recommended Dietary Allowances Revised, 1945. Reprint and circular series, number 122, August 1945, National Research Council, Washington, D.C., ya que los valores de 1945 muestran algunas reducciones, particularmente para vitaminas del complejo $\mathrm{B}$, los cálculos de porcentajes de recomendaciones de consumo de este estudio no pueden ser comparados directamente con cálculos similares basados en las recomendaciones antiguas utilizadas en otros estudios. 
Para los adultos se utilizaron recomendaciones basadas en personas con actividad moderada. Al utilizar estas recomendaciones como punto de comparación, no estamos sugiriendo que puedan ser utilizadas contra la desnutrición, ya que ese no fue el propósito para el que se elaboraron, además de que mantienen amplios rangos de tolerancia por factores de seguridad, para cubrir las variaciones individuales en los requerimientos de nutrimentos y por la falta de conocimientos precisos sobre las necesidades humanas. ${ }^{8} \mathrm{Su}$ función es la de sentar un punto de comparación y evaluación de los niveles dietéticos observados.

El cuadro 3 presenta los datos referentes a calorías. El promedio de ingestión calórica para el grupo total, incluyendo todas las edades, fue del 70 por ciento de la recomendada. Estos consumos registrados fueron menores que los encontrados en un estudio similar en la Ciudad de México, ${ }^{9}$ pero se acercan a aquéllos hallados en ciertas regiones de los Estados Unidos de América. Youmans, Patton y Kern ${ }^{10}$ encontraron un promedio de 2015 calorías para un grupo de blancos de todas las edades y de 1519 para negros en un área rural de Tennessee, y Milman y Anderson encontraron promedios de 1833 para blancos y 1598 para negros en un área rural de Carolina del Norte; estos datos son similares a nuestro promedio de 1706 . $^{*}$

\footnotetext{
* El uso del sistema de Atwater para el cálculo de valores calóricos, empleado para mezclas de dietas en los Estados Unidos, puede introducir algún error cuando se aplica a dietas más monótonas compuestas casi totalmente de plantas, como las consumidas por estas personas. Un intento por utilizar valores calóricos más específicos para los diversos alimentos trajo como resultado diferencias que difícilmente podían ser consideradas como significativas. Este error es al parecer menor que varios otros inherentes a los métodos de registro y cálculo de las ingestiones dietéticas.
}

Cuadro 3

Principales fuentes de los nUtrimentos más importantes* (De 100 registros de dietas DE 7 díAs de ACUERDo CON LA DISTRIBUCión DE EDADES Y SEXOS DEL GRUPO ESTUDIADO)

\begin{tabular}{|c|c|c|c|c|c|c|c|c|c|c|c|}
\hline Calorías & & Proteínas tot & & $\begin{array}{l}\text { Proteínas animale } \\
4.8 \% \text { del total de } p\end{array}$ & $\begin{array}{l}\text { rom. } \\
\text { inas) }\end{array}$ & Carbohidratos & & Grasas & & Vitamina A & \\
\hline & $\%$ & & $\%$ & & $\%$ & & $\%$ & & $\%$ & & $\%$ \\
\hline Tortillas & 77 & Tortillas & 73 & Carne de cabra & & Tortillas & 85 & Tortillas & 79 & Verduras de & \\
\hline Pulque ${ }^{\ddagger}$ & 12 & Frijoles & 8 & y oveja & 28 & Frijoles & 5 & Carne & 6 & hojas verdes & 52 \\
\hline Frijoles & 5 & Pulque & 6 & Carne de cerdo & 15 & Chile & 2 & Manteca & 4 & Chile & 33 \\
\hline Verduras & & Verduras de & & Pescado (seco) & 13 & Verduras & & Verduras & & Tortillas & 5 \\
\hline$y$ frutas & 2 & hojas verdes & 5 & Carne de res & 12 & $y$ frutas & I & $y$ frutas & 2 & Frutas $y$ otras & \\
\hline & & Carne & 2 & Sangre de cabra & & & & Frijoles & I & verduras & 2 \\
\hline & & Otras verduras & & u oveja & 12 & & & & & & \\
\hline & & $y$ frutas & I & Carne de pollo & & & & & & & \\
\hline & & & & y conejo & II & & & & & & \\
\hline & & & & Huevos y leche & 3 & & & & & & \\
\hline Tiamina & & Riboflavina & & Niacina & & Vitamina C & & Calcio & & Hierro & \\
\hline Tortillas & 74 & Tortillas & 48 & Tortillas & 55 & Pulque & 48 & Tortillas & 69 & Tortillas & 51 \\
\hline Pulque & 10 & Pulque & 24 & Pulque & 23 & Verduras de & & Pulque & 8 & Pulque & 20 \\
\hline Frijoles & 7 & Verduras de & & Chile & 5 & hojas verdes & 32 & Verduras de & & Verduras de & \\
\hline Frutas y & & hojas verdes & 9 & Verduras y & & Frutas y & & hojas verdes & 9 & hojas verdes & 14 \\
\hline Verduras & 4 & Frijoles & 5 & frutas & 4 & otras verduras & 7 & Frijoles & 3 & Otras verduras & 4 \\
\hline Carne & 2 & Chile & I & Carne & 2 & Chile & 4 & Otras verduras & 2 & Carne & I \\
\hline & & Frutas y otras & & & & & & & & & \\
\hline & & verduras & I & & & & & & & & \\
\hline & & Carne & I & & & & & & & & \\
\hline
\end{tabular}

\footnotetext{
* La importancia relativa de los alimentos varía poco con la edad excepto la del pulque cuyo consumo aumenta gradualmente hasta lograr un máximo en los adultos masculinos

‡ Calculado con base en el conocimiento de proteínas y alcohol. El aporte del pulque al total de calorías es probablemente un poco mayor ya que puede contener otras sustancias calóricas
} 
El promedio de consumo de calorías por 24 horas rebasa con un margen considerable a los requerimientos calóricos basales calculados según el peso y la talla, aunque en algunos grupos de edad, particularmente durante la adolescencia, el margen parece ser más bien pequeño. Una situación parecida se encontró tanto en la Ciudad de México ${ }^{9}$ como en un área rural de Tennessee. ${ }^{10}$ Sin embargo, este margen puede ser mayor de lo que en realidad aparenta, ya que los datos de Aub-Du Bois en los que se basó el cálculo de los requerimientos basales se consideran 5 o 10\% elevados aún para la población de Estados Unidos. Los indios otomíes son bajos de estatura y delgados, aunque no en su mayoría.

El cuadro 4 compara los pesos relativos de este grupo de personas, de acuerdo con la edad y el sexo, según el patrón de referencia de Estados Unidos de América, los cuales fueron en general similares a los pesos de un grupo de individuos de la Ciudad de México. ${ }^{9}$ Existen dudas sobre la conveniencia de utilizar dicho patrón en este grupo. Muchas personas, en especial las mujeres en edad adulta, tenían estaturas tan pequeñas que las tablas no podían ser utilizadas. Su exclusión posiblemente modifica los promedios; en todo caso, puede afirmarse que un elevado porcentaje, especialmente entre los niños, tenía peso bajo de acuerdo al patrón de referencia de Estados Unidos.

El cuadro 3 también muestra el porcentaje de calorías derivadas de carbohidratos, grasas, proteínas y alcohol. Se puede observar que se trata de una dieta relativamente alta en carbohidratos y baja en grasa y proteínas. Son impresionantes los porcentajes de calorías aportadas por el alcohol, prácticamente todas del pulque.

Los últimos dos renglones muestran estos datos para todo el grupo y para aquéllos cuyos registros dietéticos mostraron que habían consumido cantidades significativas en la semana de la encuesta. Sólo hay $1 \%$ de diferencia (8.0\% comparado con $9.1 \%$ ) entre el consumo de estos dos grupos. Aún entre bebés el consumo es significativo. El valor máximo de $14.8 \%$ en hombres adultos expresa el promedio y a nivel individual algunas veces fue el doble o más.

El cuadro 5 muestra que el promedio de consumo total de proteína fue de $80 \%$ de lo recomendado. Este consumo sería adecuado si se considera solamente desde el punta de vista cuantitativo; sin embargo, la situación cualitativa no es aceptable. Un promedio de sólo $4.8 \%$ provenía de fuente animal, además el $46 \%$ de las personas no consumía proteínas de origen animal y un $66 \%$ comía menos de $5 \%$ de estas. Asimismo se puede observar que no obstante que el promedio cuantitativo es aceptable, un porcentaje considerable de personas, especialmente entre los grupos de menor edad, comían menos del $50 \%$ de las recomendaciones proteicas.

El cuadro 6 proporciona datos sobre proteínas en la sangre. Con objeto de ahorrar tiempo se utilizó el método de Biuret en lugar del de Kjeldahl. Aunque el método usado es un poco menos confiable para uso generalizado, parece apropiado para el estudio de deficiencias protéicas en grupos de población, ${ }^{12}$ y en general

Cuadro 4

Relación de los pesos con los patrones de referencia de Estados Unidos*

\begin{tabular}{|c|c|c|c|c|c|c|c|c|c|c|c|c|c|}
\hline \multirow{2}{*}{\multicolumn{2}{|c|}{ Edad }} & \multicolumn{5}{|c|}{ Ambos sexos } & \multicolumn{3}{|c|}{ Sexo masculino } & \multicolumn{3}{|c|}{ Sexo femenino } & \multirow[t]{2}{*}{$\begin{array}{c}\text { Todo } \\
\text { el grupo }\end{array}$} \\
\hline & & $1-3$ & $4-6$ & $7-9$ & $10-12$ & $13-15$ & $16-20$ & $21-50$ & $50+$ & $16-20$ & $21-50$ & $50+$ & \\
\hline \multicolumn{2}{|l|}{ Número de casos } & 101 & 104 & 92 & 71 & 48 & 35 & 147 & 19 & 34 & 138 & 17 & 806 \\
\hline \multicolumn{2}{|l|}{ Peso promedio observado (kg) } & 9.5 & 14.9 & 19.4 & 27,3 & 36.3 & 50.0 & 56.6 & 55.6 & 47.4 & 48.8 & 46.6 & 35.0 \\
\hline \multicolumn{2}{|l|}{ Peso teórico $(\mathrm{kg})$} & 10.7 & 15.8 & 21.8 & 28.3 & 36.6 & 50.9 & 61.6 & 64.2 & 47.8 & 54.5 & 58.1 & 38.0 \\
\hline \multicolumn{2}{|c|}{ Proporción de peso observado en relación al teórico } & 0.89 & 0.94 & 0.89 & 0.96 & 0.99 & 0.98 & 0.92 & 0.87 & 0.99 & 0.90 & 0.80 & 0.92 \\
\hline \multirow[t]{2}{*}{ Más de 10 por ciento de déficit de peso: } & Número & 53 & 34 & 19 & 12 & 7 & 8 & 56 & 13 & 5 & 70 & 13 & 290 \\
\hline & Porcentaje & 53 & 33 & 21 & 17 & 15 & 23 & 38 & 68 & 15 & 51 & 76 & 36 \\
\hline \multirow[t]{2}{*}{ Más de 10 por ciento de sobre-peso: } & Número & & 3 & 5 & 0 & 5 & 2 & 3 & 2 & 4 & 2 & 0 & 27 \\
\hline & Porcentaje & & 3 & 5 & 0 & 10 & 6 & 2 & 10.5 & 12 & 1.5 & 0 & 3.3 \\
\hline
\end{tabular}

Personas en las que las tablas de referencia no eran aplicables:

\begin{tabular}{|c|c|c|c|c|c|c|c|c|c|c|}
\hline Número & 7 & 3 & 0 & 1 & 6 & 17 & 14 & 45 & 47 & 142 \\
\hline Porcentaje & 7 & 3 & 0 & 3 & 4 & 47 & 29 & 25 & 73 & 15 \\
\hline
\end{tabular}


Cuadro 5

\section{CONSUMO de PROTEÍNAS}

\begin{tabular}{|c|c|c|c|c|c|c|c|c|c|c|c|c|c|}
\hline \multirow[b]{2}{*}{ Edad } & \multicolumn{4}{|c|}{ Ambos sexos } & \multicolumn{4}{|c|}{ Sexo masculino } & \multicolumn{4}{|c|}{ Sexo femenino } & \multirow{2}{*}{$\begin{array}{l}\text { Todo el } \\
\text { grupo }\end{array}$} \\
\hline & $1-3$ & $4-6$ & $7-9$ & $10-12$ & $13-15$ & $16-20$ & $21-50$ & $50+$ & $13-15$ & $16-20$ & $21-50$ & $50+$ & \\
\hline Número de personas & 62 & 102 & 87 & 72 & 25 & 35 & 147 & 43 & 22 & 39 & 169 & 53 & 856 \\
\hline Promedio de gramos de proteína al día & 28.6 & 33.8 & 37.8 & 45.4 & 55.8 & 61.9 & 71.8 & 62.2 & 47.1 & 56.6 & 54.9 & 49.1 & 51.0 \\
\hline Error estándar de la media & 1.2 & 1.2 & 1.4 & 1.9 & 3.0 & 4.4 & 1.9 & 3.5 & 2.7 & 2.8 & 1.6 & 2.0 & 0.77 \\
\hline $\begin{array}{l}\text { Consumo recomendado por el National Research } \\
\text { Council (gramos) }\end{array}$ & 40 & 50 & 60 & 70 & 85 & 100 & 70 & 70 & 80 & 75 & 60 & 60 & 64.0 \\
\hline Porcentaje del consumo recomendado & 72 & 68 & 63 & 65 & 66 & 62 & 102 & 89 & 59 & 75 & 92 & 82 & 80 \\
\hline $\begin{array}{l}\text { Porcentaje de personas con consumo inferior al } \\
\text { recomendado }\end{array}$ & 85.5 & 88.2 & 92.0 & 87.5 & 100.0 & 94.3 & 46.9 & 60.5 & 100.0 & 84.6 & 71.0 & 77.4 & 76.5 \\
\hline $\begin{array}{l}\text { Porcentaje de personas con consumo inferior al } 50 \text { por } \\
\text { ciento de las recomendaciones }\end{array}$ & 16.1 & 19.6 & 26.4 & 27.8 & 24.0 & 42.9 & 0.7 & 4.7 & 36.4 & 25.6 & 2.4 & 3.8 & | 4.1 \\
\hline Porcentaje de proteínas animales consumidas & 6.4 & 3.4 & 5.2 & 5.6 & 6.9 & 4.2 & 4.6 & 2.6 & 5.5 & 6.6 & 4.6 & 5.2 & 4.8 \\
\hline $\begin{array}{l}\text { Porcentaje de personas que no consumian proteínas } \\
\text { animales }\end{array}$ & 58 & 51 & 42 & 33 & 56 & 40 & 44 & 47 & 36 & 41 & 46 & 56 & 46 \\
\hline $\begin{array}{l}\text { Porcentaje de personas que consumían } \\
\text { menos de } 5 \text { por ciento de proteína animal }\end{array}$ & 63 & 66 & 72 & 60 & 57 & 73 & 64 & 83 & 52 & 56 & 66 & 71 & 66 \\
\hline
\end{tabular}

\section{Cuadro 6}

\section{Proteínas séricas}

\begin{tabular}{|c|c|c|c|c|c|c|c|c|}
\hline \multirow[b]{2}{*}{ Edad } & \multicolumn{2}{|c|}{ Ambos sexos } & \multicolumn{2}{|c|}{ Sexo masculino } & \multicolumn{2}{|c|}{ Sexo femenino } & \multirow[b]{2}{*}{$\begin{array}{c}\text { Lactantes y } \\
\text { embarazadas }\end{array}$} & \multirow[b]{2}{*}{ Todo el grupo } \\
\hline & $1-9$ & $10-15$ & $16-50$ & $50+$ & $16-50$ & $50+$ & & \\
\hline Número de personas & 200 & 117 & 187 & 36 & 139 & 63 & 89 & 831 \\
\hline Proteínas totales $\mathrm{g} / \mathrm{l} 00 \mathrm{ml}$ & 7.39 & 7.38 & 7.61 & 7.38 & 7.43 & 7.44 & 7.21 & 7.43 \\
\hline Error estándar de la media & 0.047 & 0.067 & 0.055 & 0.13 & 0.076 & 0.12 & 0.078 & 0.027 \\
\hline Porcentaje abajo de $6.5 \mathrm{~g}$ & 7.0 & 7.7 & 5.9 & 10.1 & 12.2 & 12.7 & 16.9 & 9.4 \\
\hline Porcentaje abajo de $6 \mathrm{~g}$ & 2.5 & 5.1 & 3.7 & 0 & 7.9 & 7.9 & 5.6 & 4.7 \\
\hline Albúmina g/ I 00 m l & 4.99 & 4.93 & 4.81 & 4.23 & 4.75 & 4.39 & 4.62 & 4.78 \\
\hline Error estándar de la media & 0.038 & 0.055 & 0.049 & 0.13 & 0.056 & 0.092 & 0.064 & 0.023 \\
\hline Porcentaje abajo de $4.0 \mathrm{~g}$ & 5.0 & 6.0 & 9.1 & 38.9 & 10.0 & 25.4 & 13.5 & 11.0 \\
\hline Porcentaje abajo de $3.5 \mathrm{~g}$ & 2.0 & 4.3 & 3.7 & 11.1 & 5.7 & 11.1 & 4.5 & 4.7 \\
\hline
\end{tabular}

los valores se comparan favorablemente con los de otros estudios. ${ }^{9,11,12, *}$

Aproximadamente en un 10\% de los casos se puede considerar que existen valores bajos de proteína (proteína total menor de $6.5 \mathrm{mg}$, albumina menor de $4.0 \mathrm{mg}$ ),

\footnotetext{
* Hurtado y colaboradores ${ }^{23}$ observaron un aumento moderado pero definitivo en proteínas séricas después de tres horas de llegar a una gran altitud. Los efectos crónicos de la altitud deben ser determinados antes de que estos valores protéicos puedan ser comparados con los de otros lugares.
}

pero la deficiencia rara vez fue grave, y no se observó en forma marcada en mujeres embarazadas y lactantes, en quienes muy probablemente se haría evidente una deficiencia. El grupo de niveles más bajos fue el de personas mayores de 50 años, cerca de $40 \%$ de este grupo de edad tuvieron valores de albumina inferiores a 4 g. Sólo 14 adultos mostraron evidencia clínica de edema moderado; de estos, 6 tenían niveles de proteínas en sangre lo suficientemente bajos como para considerarlos factor importante en la causa del edema (promedio de proteína total de $5.1 \mathrm{mg}$ y albumina de $2.6 \mathrm{~g}$ ). El edema en los otros casos debe ser atribuido a otras causas. Desde el 
punto de vista del consumo de proteínas, los niveles de proteína en sangre y los exámenes clínicos, la nutrición proteica de estas personas era bastante buena.

La mayor fuente de proteínas era la tortilla, seguida de frijoles y pulque, los que tenían menos importancia (cuadro 2). Entre las proteínas vegetales, la proteína del maíz (si el germen es incluido como en la preparación de la tortilla ${ }^{13}$ ) y el frijol pueden considerarse como de valor biológico aceptable. El contenido de proteínas del pulque fue calculado por su contenido de nitrógeno; dado que existe la posibilidad de que el pulque contenga otros productos nitrogenados no proteínicos, probablemente el valor asignado fue demasiado alto. Se sabe que las proteínas de algunos microorganismos fermentadores son deficientes en aminoácidos azufrados ${ }_{,}^{14}$ sin embargo se duda de que exista esta deficiencia en el pulque.

Es posible que una deficiencia en la calidad o cantidad de la proteína consumida pudo haber afectado negativamente el crecimiento de estas personas, sin disminuir significativamente los niveles de proteína en sangre. Se sabe que esto ocurre en animales experimentales. ${ }^{15} \mathrm{EI}$ crecimiento era inadecuado si se juzga a través de los patrones de crecimiento de los Estados Unidos de América, con retardos en el crecimiento de entre dos y tres años. ${ }^{16}$

El cuadro 7 muestra el consumo de vitamina A. Este nutrimento se encontraba presente casi en su totalidad en forma de provitamina A (caroteno). Aparentemente las cantidades consumidas eran adecuadas, encontrándose un consumo de $127 \%$ de lo recomendado, sin embargo se reconoce que los requerimientos pueden ser mayores si se satisfacen fundamentalmente con carotenos en lugar de hacerlo con vitamina A. Por otro lado, al menos $13 \%$ de las personas comieron menos del $50 \%$ de los alimentos recomendados.
El cuadro 8 proporciona los datos de vitamina A y caroteno en sangre. En general los valores de vitamina A corresponden a los encontrados en cualquier otro lugar, aumentando paulatinamente de la niñez a la edad adulta. ${ }^{9,11,17}$ El porcentaje por debajo de 70 U.I. fue de 25; sin embargo, creemos que es un límite elevado, particularmente para niños en los que $50 \mathrm{U}$. I. parece un mínimo más satisfactorio. En este mismo cuadro se incluye la proporción de personas con niveles inferiores a 30 U.I., ya que la deficiencia clásica de vitamina A no se presenta generalmente arriba de este nivel.

Se encontraron pocos signos clínicos de deficiencia de vitamina A y éstos fueron indefinidos. Aunque la presencia de piel seca era muy común, esta condición puede atribuirse a factores higiénicos y físicos. Se encontraron veinte personas con piel seca hiperqueratósica, posiblemente de origen nutricional; empero, ni su consumo de vitamina A ni sus niveles de sangre eran bajos. No se encontraron signos clásicos de deficiencia como las manchas de Bitol, aunque la incidencia de alteraciones de la conjuntiva fue alta (cuadro 18), estas pueden no ser una expresión de deficiencia en vitamina A, y como se encontró previamente con otros signos, no existieron correlaciones entre estas alteraciones y los niveles de alimento en la dieta y la sangre. ${ }^{19}$

Tal como se presenta en el cuadro 9, el consumo de tiamina fue adecuado aun con una dieta tan elevada en carbohidratos. En todos los grupos de edad el promedio alcanzó o excedió las recomendaciones y sólo una persona recibió menos del 50 por ciento. Además, los miligramos de tiamina por 1000 calorías superaban el valor frecuentemente recomendado de $0.50 .6 \mathrm{mg},{ }^{20}$ y estaba lejos de la zona considerada comúnmente de peligro de $0.2 \mathrm{mg}$ por 1000 calorías. No se observaron casos con deficiencia de tiamina, aunque se encontró una elevada

Cuadro 7

Consumo de vitamina A

\begin{tabular}{|c|c|c|c|c|c|c|c|c|c|c|c|c|c|}
\hline \multirow[b]{2}{*}{ Edad } & \multicolumn{4}{|c|}{ Ambos Sexos } & \multicolumn{4}{|c|}{ Sexo masculino } & \multicolumn{4}{|c|}{ Sexo femenino } & \multirow{2}{*}{$\begin{array}{l}\text { Todo el } \\
\text { grupo }\end{array}$} \\
\hline & $1-3$ & $4-6$ & $7-9$ & $10-12$ & $13-15$ & $16-20$ & $21-50$ & $50+$ & $13-15$ & $16-20$ & $21-50$ & $50+$ & \\
\hline Número de personas & 62 & 102 & 87 & 72 & 25 & 35 & 147 & 43 & 22 & 39 & 169 & 53 & 856 \\
\hline Consumo diario promedio (U.I.) & 3799 & 4332 & 4595 & 5035 & 5170 & 5556 & 6897 & 5634 & 4773 & 5699 & 6218 & 5821 & 5498 \\
\hline Error estándar de la media & 310 & 272 & 341 & 324 & 524 & 511 & 418 & 540 & 517 & 471 & 374 & 531 & 138 \\
\hline $\begin{array}{l}\text { Consumo recomendado por el Na- } \\
\text { tional Research Council }\end{array}$ & 2000 & 2500 & 3500 & 4500 & 5000 & 6000 & 5000 & 5000 & 5000 & 5000 & 5000 & 5000 & 4331 \\
\hline $\begin{array}{l}\text { Porcentaje del consumo recomen- } \\
\text { dado }\end{array}$ & 190 & 173 & $|3|$ & 112 & 103 & 93 & 138 & 113 & 95 & 114 & 124 & 116 & 127 \\
\hline $\begin{array}{l}\text { Porcentaje de personas con consumo } \\
\text { inferior al recomendado }\end{array}$ & 25 & 30 & 48 & 57 & 56 & 68 & 39 & 46 & 59 & 49 & 49 & 53 & 45 \\
\hline $\begin{array}{l}\text { Porcentaje de personas con consu- } \\
\text { mo inferior al } 50 \text { por ciento de lo } \\
\text { recomendado }\end{array}$ & 6 & 6 & 17 & 11 & 12 & 20 & 14 & 26 & 9 & 9 & 16 & 11 & 13 \\
\hline
\end{tabular}


Cuadro 8

VITAMINA A Y CAROTENO EN SANGRE

\begin{tabular}{|c|c|c|c|c|c|c|c|c|c|c|c|c|c|}
\hline \multirow[b]{2}{*}{ Edad } & \multicolumn{4}{|c|}{ Ambos sexos } & \multicolumn{4}{|c|}{ Sexo masculino } & \multicolumn{4}{|c|}{ Sexo femenino } & \multirow{2}{*}{$\begin{array}{c}\text { Todo el } \\
\text { grupo }\end{array}$} \\
\hline & $1-3$ & $4-6$ & $7-9$ & $10-12$ & $13-15$ & $16-20$ & $21-50$ & $50+$ & $16-20$ & $21-50$ & $50+$ & $\begin{array}{c}\text { Lactantes } \\
\text { y embara- } \\
\text { zadas }\end{array}$ & \\
\hline Número de personas & 22 & 78 & 86 & 70 & 45 & 35 & 150 & 36 & 24 & III & 63 & 90 & 809 \\
\hline \multicolumn{14}{|l|}{ Promedio de niveles de vitamina $\mathrm{A}$} \\
\hline sérica (U.I.) & 73 & 69 & 78 & 87 & 91 & 111 & 126 & 87 & 102 & 105 & 102 & 105 & 98 \\
\hline Error estándar de la media & 7.4 & 2.8 & 3.6 & 4.6 & 3.4 & 5.4 & 3.4 & 6.8 & 13.0 & 3.6 & 5.3 & 4.2 & 1.4 \\
\hline Porcentaje por abajo de 70 U.I. & 59 & 51 & 44 & 27 & 20 & 6 & 9 & 36 & 21 & 17 & 22 & 21 & 25 \\
\hline Porcentaje por abajo de 50 U.I. & 27 & 27 & 17 & 7 & 2 & 3 & 2 & 19 & 4 & 12 & 12 & 4 & 10 \\
\hline Porcentaje por abajo de 30 U.I. & 4.5 & 1.3 & 2.3 & 1.4 & 0 & 0 & 0.7 & 8.3 & 0 & 2.7 & 1.6 & I.I & 1.7 \\
\hline \multicolumn{14}{|l|}{ Promedio de caroteno sérico } \\
\hline (microgramos) & 136 & 158 & 156 & 149 & 138 & 82 & 80 & 64 & 132 & 120 & 118 & 136 & 122 \\
\hline Error estándar de la media & 19.0 & 7.9 & 6.9 & 7.7 & 9.8 & 9.1 & 3.8 & 5.8 & 10.0 & 6.1 & 8.5 & 7.5 & 2.4 \\
\hline
\end{tabular}

Cuadro 9

Consumo de tiamina A

\begin{tabular}{|c|c|c|c|c|c|c|c|c|c|c|c|c|c|}
\hline \multirow[b]{2}{*}{ Edad } & \multicolumn{4}{|c|}{ Ambos sexos } & \multicolumn{4}{|c|}{ Sexo masculino } & \multicolumn{4}{|c|}{ Sexo femenino } & \multirow{2}{*}{$\begin{array}{l}\text { Todo e } \\
\text { grupo }\end{array}$} \\
\hline & $1-3$ & $4-6$ & $7-9$ & $10-12$ & $13-15$ & $16-20$ & $21-50$ & $50+$ & $13-15$ & $16-20$ & $21-50$ & $50+$ & \\
\hline Número de personas & 62 & 102 & 87 & 72 & 25 & 35 & 147 & 43 & 22 & 39 & 169 & 53 & 856 \\
\hline \multicolumn{14}{|l|}{ Consumo promedio de tiamina } \\
\hline al dia (mg) & 0.86 & 1.0 & 1.2 & 1.4 & 1.7 & 2.0 & 2.4 & 2.0 & 1.6 & 1.7 & 1.7 & 1.5 & 1.61 \\
\hline Error estándar de la media & 0.035 & 0.035 & 0.051 & 0.060 & 0.086 & 0.145 & 0.073 & 0.114 & 0.153 & 0.090 & 0.048 & 0.069 & 0.027 \\
\hline \multicolumn{14}{|l|}{ Consumo recomendado } \\
\hline por el National Research Council & 0.6 & 0.8 & 1.0 & 1.2 & 1.5 & 1.8 & 1.5 & 1.5 & 1.3 & 1.2 & 1.2 & 1.2 & 1.19 \\
\hline Porcentaje del consumo recomenda & ado 143 & 125 & 120 & 117 & 113 & III & 160 & 133 & 123 & 142 & 142 & 125 & 135 \\
\hline \multicolumn{14}{|l|}{ Porcentaje de personas con } \\
\hline consumo inferior al recomendado & 8 & 23 & 21 & 42 & 32 & 49 & 14 & 23 & 41 & 18 & 14 & 28 & 22 \\
\hline \multicolumn{14}{|l|}{$\begin{array}{l}\text { Porcentaje de personas con } \\
\text { consumo inferior al } 50 \text { por }\end{array}$} \\
\hline ciento de lo recomendado & 0 & 1.0 & 0 & 0 & 0 & 0 & 0 & 0 & 0 & 0 & 0 & 0 & 0.1 \\
\hline mg de tiamina por I 000 calorías & 0.90 & 0.89 & 0.94 & 0.92 & 1.03 & 0.95 & 0.98 & 0.93 & 1.04 & 0.94 & 0.93 & 0.93 & 0.94 \\
\hline
\end{tabular}

incidencia de síntomas atribuidos ocasionalmente a esta deficiencia y de dolores en los músculos de las piernas (cuadro 19); difícilmente puede juzgarse si estos signos o síntomas por sí mismos constituyen una evidencia de deficiencia de tiamina, especialmente en un grupo como este, cuyo nivel intelectual dificulta aún más la evaluación. No hubo casos de neuritis periférica definida.

En el cuadro 10 puede observarse que el consumo de riboflavina era definitivamente bajo, siendo en promedio de $41 \%$ de las recomendaciones, con $98 \%$ de las personas consumiendo menos de lo recomendado y $69 \%$ menos del 50\% de las recomendaciones. El promedio de miligramos de riboflavina por 1000 calorías se encuentra ligeramente por arriba de un valor que produce agotamiento gradual de las reservas del cuerpo, ${ }^{21}$ y los valores de consumo de algunas personas se encontraban muy por debajo de este promedio.

Los análisis de los alimentos mexicanos han indicado que puede esperarse una deficiencia de riboflavina; ${ }^{1}$ esto se confirma por los hallazgos clínicos de una gran frecuencia de queilosis angular y glositis (cuadros 18 y 19). La incidencia de vascularización de la córnea 


\section{Cuadro 10}

\section{Consumo de RIBOFLAVINA}

\begin{tabular}{|c|c|c|c|c|c|c|c|c|c|c|c|c|c|}
\hline \multirow[b]{2}{*}{ Edad } & \multicolumn{4}{|c|}{ Ambos sexos } & \multicolumn{4}{|c|}{ Sexo masculino } & \multicolumn{4}{|c|}{ Sexo femenino } & \multirow{2}{*}{$\begin{array}{r}\text { Todo el } \\
\text { grupo }\end{array}$} \\
\hline & $1-3$ & $4-6$ & $7-9$ & $10-12$ & $13-15$ & $16-20$ & $21-50$ & $50+$ & $13-15$ & $16-20$ & $21-50$ & $50+$ & \\
\hline Número de personas & 62 & 102 & 87 & 72 & 25 & 35 & 147 & 43 & 22 & 39 & 169 & 53 & 856 \\
\hline \multicolumn{14}{|l|}{ Consumo promedio diario } \\
\hline de riboflavina (mg) & 0.35 & 0.40 & 0.48 & 0.57 & 0.67 & 0.89 & 1.10 & 0.89 & 0.63 & 0.73 & 0.71 & 0.72 & 0.69 \\
\hline Error estándar de la media & 0.025 & 0.015 & 0.023 & 0.025 & 0.045 & 0.078 & 0.042 & 0.058 & 0.051 & 0.054 & 0.029 & 0.045 & 0.017 \\
\hline \multicolumn{14}{|l|}{ Consumo recomendado } \\
\hline por el National Research Council & 0.9 & 1.2 & 1.5 & 1.8 & 2.0 & 2.5 & 2.0 & 2.0 & 2.0 & 1.8 & 1.6 & 1.6 & 1.66 \\
\hline Porcentaje del consumo recomendado & 39 & 33 & 32 & 32 & 34 & 36 & 55 & 45 & 32 & 41 & 44 & 45 & 41 \\
\hline \multicolumn{14}{|l|}{ Porcentaje de personas con consumos } \\
\hline inferiores a los recomendados & 100 & 100 & 99 & 100 & 100 & 100 & 95 & 100 & 100 & 97 & 96 & 94 & 98 \\
\hline \multicolumn{14}{|l|}{ Porcentaje de personas con consumos por } \\
\hline abajo del 50 por ciento de lo recomendado & lo 76 & 85 & 95 & 93 & 84 & 80 & 45 & 60 & 86 & 69 & 50 & 62 & 69 \\
\hline $\mathrm{mg}$ de ribof lavina por I 000 calorías & 0.368 & 0.357 & 0.377 & 0.375 & 0.407 & 0.424 & 0.448 & 0.415 & 0.411 & 0.401 & 0.388 & 0.446 & 0.404 \\
\hline
\end{tabular}

fue de 42 por ciento (cuadro 18). Esta es menor que la encontrada en grupos de blancos, pero mayor que en los negros de los Estados Unidos, donde el consumo de riboflavina era considerablemente más elevado. ${ }^{11,19} \mathrm{El}$ posible efecto de la raza obstaculiza la evaluación de la incidencia de vascularización de la córnea en estos grupos indígenas; sin embargo, no se observó correlación entre el consumo de riboflavina y la vascularización de la córnea u otros signos que sugieren deficiencia de riboflavina.

El consumo de niacina (cuadro 11) fue bajo si se juzga utilizando las recomendaciones, pero estaba muy por encima del nivel que generalmente produce pelagra. La situación aquí es complicada debido a que las tortillas, hechas de maíz, aportan alrededor de tres cuartas partes de las calorías y es posible que bajo tales condiciones el consumo de niacina pueda ser deficiente. Aunque no se encontró pelagra clásica, fue común observar resequedad de la piel en los pies y espinillas. La incidencia de glositis fue alta (cuadro 18), pudiendo considerarse como factores de esta las deficiencias de niacina y riboflavina.

El consumo de vitamina $C$ puede considerarse bueno (cuadro 12), alcanzándose un promedio de 142\% de lo recomendado. Ningún grupo cayó por debajo de $75 \%$, que es un nivel casi adecuado, el consumo elevado en los adultos se debe a la excesiva ingestión de pulque; los niveles en sangre resultaron congruentes con los consumos de vitamina C, observándose promedios bastante superiores a $1 \mathrm{mg}$ para todos los grupos de edad, con un porcentaje relativamente pequeño con consumos de 0.6 mg y sólo $1.6 \%$ por debajo de $0.3 \mathrm{mg}$ (cuadro 13). Sólo se encontraran dos valores de cero durante todo el estudio, uno en una persona que no bebía pulque y otro en una persona con paludismo activo. Estos datos contrastan con varios estudios hechos en los Estados Unidos, en los que se encontraron comúnmente valores de cero. ${ }^{11,12}$

No se encontraron casos considerados como escorbuto al practicar exámenes físicos. No obstante los consumos relativamente altos de vitamina $\mathrm{C}$ y los valores en sangre, era extremadamente común encontrar encías rojas, hinchadas y esponjosas.

La incidencia de gingivitis, determinada por examen con una lámpara de exploración física, se aprecia en el cuadro 18 y juzgada por examen dental en el cuadro 20. Se piensa que esta incidencia elevada debe atribuirse a la mala higiene dental y no a deficiencias de vitamina C; prácticamente no existían cepillos de dientes o cuidados dentales. Tampoco se encontró correlación entre la gingivitis y los niveles de vitamina $\mathrm{C}$ en dieta o en sangre.

El cuadro 14 proporciona información que indica que los valores hematológicos son adecuados si se comparan con los encontrados habitualmente en Estados Unidos; sin embargo, no existen estudios realizados en altitudes similares que puedan ser utilizados con fines comparativos, por lo que es difícil emitir un juicio definitivo. Al parecer no fue común la incidencia de anemia. Debe añadirse que en esta región no existe una incidencia de uncinaria tal que obligue a considerar a este parásito como un factor a tomar en cuenta al analizar los valores hematológicos. El promedio de dichos valores en mujeres embarazadas y en lactancia no fue significativamente menor al de otras mujeres, lo 
Cuadro II

CONSUMO DE NIACINA

Edad

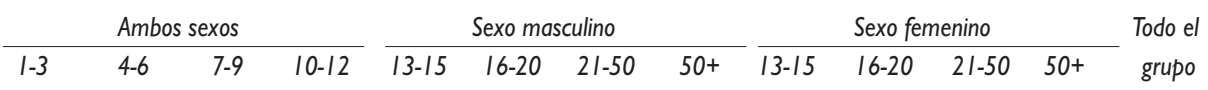

Número de personas $\begin{array}{lllllllllllll}62 & 102 & 87 & 72 & 25 & 35 & 147 & 43 & 22 & 39 & 169 & 53 & 856\end{array}$

Consumo promedio diario

Error estándar de la media

$\begin{array}{llll}4.6 & 5.2 & 6.0 & 7.7\end{array}$

Consumo recomendado por

el National Research Council

Porcentaje del consumo recomendado 77

Porcentaje de personas con consumos

$\begin{array}{llllllllllllll}\text { inferiores a los recomendados } & 74 & 87 & 97 & 89 & 92 & 91 & 54 & 72 & 91 & 69 & 68 & 79 & 76\end{array}$

Porcentaje de personas con

consumos inferiores al 50 por ciento

de lo recomendado

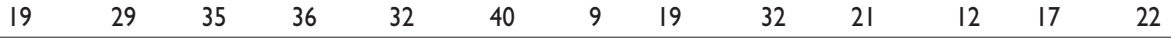

Cuadro 12

Consumo de vitamina C

Edad

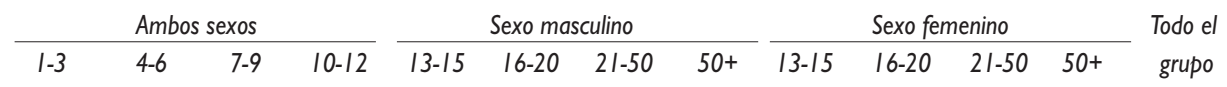

Número de personas

$\begin{array}{lllllllllllll}62 & 102 & 87 & 72 & 25 & 35 & 147 & 43 & 22 & 39 & 169 & 53 & 856\end{array}$

Consumo promedio diario

de vitamina $\mathrm{C}(\mathrm{mg})$ $9.9 \quad 41.8 \quad 44.8 \quad 61.7$

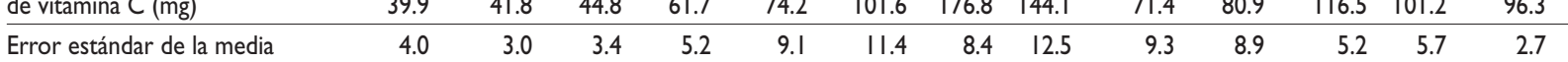

Consumo recomendado por

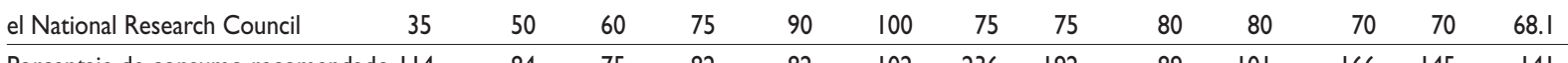

\begin{tabular}{lllllllllllll}
\hline Porcentaje de consumo recomendado II4 & 84 & 75 & 82 & 82 & 102 & 236 & 192 & 89 & 101 & 166 & 145 & $14 \mid$
\end{tabular}

Porcentaje de personas

con consumo inferior al recomendado $\begin{array}{lllllllllllll}52 & 70 & 75 & 36 & 68 & 51 & \mid 4 & 12 & 64 & 54 & 21 & 23 & 40\end{array}$

Porcentaje de personas con

consumo inferior al 50 por ciento

de lo recomendado

$15 \quad 36$

23

Cuadro 13

Niveles de vitamina $C$ en sangre

Edad

$\frac{\text { Ambos sexos }}{1-9 \quad 10-15} \frac{\text { Sexo masculino }}{16 \text { años y más }}$

\begin{tabular}{cr} 
Sexo femenino & Todo el \\
\hline 16 años y más Embarazadas y lactantes & grupo
\end{tabular}

\begin{tabular}{|c|c|c|c|c|c|c|}
\hline Número de personas & 205 & 118 & 223 & 203 & 90 & 839 \\
\hline \multicolumn{7}{|c|}{ Niveles promedio de vitamina C } \\
\hline$(\mathrm{mg} / \mathrm{l} 00 \mathrm{ml})$ & 1.16 & 1.28 & 1.18 & 1.22 & 1.14 & 1.19 \\
\hline Error estándar de la media & 0.029 & 0.033 & 0.030 & 0.027 & 0.039 & 0.014 \\
\hline Porcentaje abajo de $0.6 \mathrm{mg}$ & 9.7 & 4.3 & 13.9 & 7.4 & 4.4 & 8.9 \\
\hline Porcentaje abajo de $0.3 \mathrm{mg}$ & 1.9 & 0.8 & 2.2 & 1.5 & I.I & 1.6 \\
\hline
\end{tabular}


que sugiere que el consumo de alimentos con materias para la síntesis de hemoglobina, especialmente hierro, era suficiente para cubrir los requerimientos extra de estos periodos.

El volumen corpuscular medio y la hemoglobina corpuscular media muestran valores moderadamente superiores a los habituales; esto puede atribuirse a la altitud y coincide con algunos otros estudios; ${ }^{9,13,24}$ los registros del consumo de hierro (cuadro 15) apoyan los datos hematológicos. El consumo se encontraba por arriba en todos los grupos de edad y la incidencia de consumos bajos era reducida.

El calcio y el fósforo (cuadro 16) son aportados principalmente por las tortillas. El promedio del consumo de calcio es de $85 \%$ de las recomendaciones, considerándose como adecuado; sin embargo, en los niños pequeños el promedio desciende a 50\% de las recomendaciones y la incidencia de bajos consumos es elevada. Los niños amamantados (prácticamente todos los menores de un año y otros niños mayores) no fueron incluidos en el estudio, debido a la dificultad en la determinación de su consumo de alimentos; sin embargo, como los consumos de las madres fueron por regla general adecuados, probablemente los de los niños amamantados también lo eran. No se encontró ningún caso de raquitismo o enfermedad atribuida a deficiencia de calcio. Al parecer, el consumo de fósforo era adecuado y la relación calcio-fósforo era

\begin{tabular}{|c|c|c|c|c|c|c|}
\hline \multirow[b]{3}{*}{ Edad } & \multicolumn{5}{|c|}{$\begin{array}{c}\text { Cuadro I4 } \\
\text { VALORES HEMATOLÓGICOS }\end{array}$} & \multirow{3}{*}{$\begin{array}{l}\text { Todo el } \\
\text { grupo }\end{array}$} \\
\hline & \multicolumn{2}{|c|}{ Ambos sexos } & \multirow{2}{*}{$\begin{array}{l}\text { Sexo masculino } \\
16 \text { años y más }\end{array}$} & \multicolumn{2}{|c|}{ Sexo femenino } & \\
\hline & $1-9$ & $10-15$ & & 16 años y más & Embarazadas y lactantes & \\
\hline Número de personas & 214 & 118 & 223 & 205 & 92 & 852 \\
\hline Promedio de hemoglobina $\mathrm{g} / 100 \mathrm{ml}$ & 13.2 & 14.2 & 15.5 & 13.8 & 13.7 & 14.1 \\
\hline Error estándar de la media & 0.036 & 0.051 & 0.036 & 0.031 & 0.045 & 0.034 \\
\hline Porcentaje inferior a $12 \mathrm{~g}$ & 10.3 & 5.1 & 1.8 & 2.4 & 4.3 & 4.8 \\
\hline Porcentaje inferior a $10 \mathrm{~g}$ & 2.3 & 3.4 & 0.4 & 1.0 & 1.1 & 1.5 \\
\hline Media de glóbulos rojos (en millones) & 4.30 & 4.51 & 4.81 & 4.57 & 4.47 & 4.55 \\
\hline Error estándar de la media & 0.027 & 0.033 & 0.029 & 0.022 & 0.035 & 0.015 \\
\hline Media de hematócrito & 39 & 41 & 45 & 42 & 41 & 42 \\
\hline Error estándar de la media & 0.25 & 0.34 & 0.26 & 0.19 & 0.33 & 0.14 \\
\hline
\end{tabular}

Cuadro 15

Consumo de hierro

\begin{tabular}{|c|c|c|c|c|c|c|c|c|c|c|c|c|c|}
\hline \multirow[b]{2}{*}{ Edad } & \multicolumn{4}{|c|}{ Ambos sexos } & \multicolumn{4}{|c|}{ Sexo masculino } & \multicolumn{4}{|c|}{ Sexo femenino } & \multirow{2}{*}{$\begin{array}{l}\text { Todo e } \\
\text { grupo }\end{array}$} \\
\hline & $1-3$ & $4-6$ & $7-9$ & $10-12$ & $13-15$ & $16-20$ & $21-50$ & $50+$ & $13-15$ & $16-20$ & $21-50$ & $50+$ & \\
\hline Número de personas & 62 & 102 & 87 & 72 & 25 & 35 & 147 & 43 & 22 & 39 & 169 & 53 & 856 \\
\hline \multicolumn{14}{|l|}{ Media del consumo promedio } \\
\hline de hierro al día (mg) & 12.5 & 12.9 & 14.2 & 18.7 & 20.7 & 28.3 & 36.3 & 30.3 & 19.5 & 23.6 & 26.4 & 22.6 & 23.2 \\
\hline Error estándar de la media & 0.50 & 0.45 & 0.57 & 0.95 & 1.5 & 2.06 & 1.32 & 1.97 & 1.16 & 1.50 & 0.96 & 1.2 & 0.45 \\
\hline \multicolumn{14}{|l|}{ Consumo recomendado por } \\
\hline el National Research Council & 7 & 8 & 10 & 12 & 15 & 15 & 12 & 12 & 15 & 15 & 12 & 12 & 11.4 \\
\hline \multicolumn{14}{|l|}{ Porcentaje del consumo } \\
\hline recomendado & 179 & 161 & 142 & 156 & 138 & 189 & 302 & 252 & 130 & 157 & 220 & 189 & 204 \\
\hline \multicolumn{14}{|l|}{ Porcentaje de personas con } \\
\hline consumo inferior al recomendado & 19 & 15 & 20 & 18 & 16 & 8.6 & 2 & 2.3 & 18 & 15 & 4.7 & 3.8 & 10 \\
\hline
\end{tabular}

Porcentaje de personas con

consumo inferior al 50 por ciento

de lo recomendado

4.8

$4.8 \quad 0-1.1$

0

$0.7 \quad 0$

$\begin{array}{lllll}0 & 2.6 & 0 & 0 & 0.7\end{array}$


Cuadro 16

\section{Consumo de CALCIO Y FósForo}

\begin{tabular}{|c|c|c|c|c|c|c|c|c|c|c|c|c|c|}
\hline \multirow[b]{2}{*}{ Edad } & \multicolumn{4}{|c|}{ Ambos sexos } & \multicolumn{4}{|c|}{ Sexo masculino } & \multicolumn{4}{|c|}{ Sexo femenino } & \multirow{2}{*}{$\begin{array}{r}\text { Todo e } \\
\text { grupo }\end{array}$} \\
\hline & $1-3$ & $4-6$ & $7-9$ & $10-12$ & $13-15$ & $16-20$ & $21-50$ & $50+$ & $13-15$ & $16-20$ & $21-50$ & $50+$ & \\
\hline Número de personas & 62 & 102 & 87 & 72 & 25 & 35 & 147 & 43 & 22 & 39 & 169 & 53 & 856 \\
\hline Consumo promedio de calcio al día (g) & 0.49 & 0.51 & 0.61 & 0.72 & 0.81 & 1.08 & 1.14 & 1.00 & 0.76 & 0.88 & 0.90 & 0.78 & 0.82 \\
\hline Error estándar de la media & 0.020 & 0.021 & 0.022 & 0.029 & 0.052 & 0.065 & 0.037 & 0.053 & 0.053 & 0.050 & 0.011 & 0.028 & 0.012 \\
\hline \multicolumn{14}{|l|}{ Consumo recomendado por el National } \\
\hline Research Council & 1.0 & 1.0 & 1.0 & 1.2 & 1.4 & 1.4 & 0.8 & 0.8 & 1.3 & 1.0 & 0.8 & 0.8 & 0.96 \\
\hline Porcentaje de consumos recomendados & 49 & 51 & 61 & 60 & 58 & 77 & 142 & 125 & 58 & 88 & 112 & 98 & 85 \\
\hline \multicolumn{14}{|l|}{ Porcentaje de personas con consumos } \\
\hline inferiores a los recomendados & 92 & 96 & 93 & 92 & 100 & 80 & 12 & 28 & 100 & 54 & 32 & 47 & 59 \\
\hline \multicolumn{14}{|l|}{$\begin{array}{l}\text { Porcentaje de personas con consumos por } \\
\text { consumos por abajo del } 50\end{array}$} \\
\hline por ciento de lo recomendado & 42 & 29 & 22 & 21 & 24 & 11 & 2 & 2 & 36 & 5 & 1 & 4 & 11 \\
\hline Consumo promedio de fósforo al día & 0.61 & 0.69 & 0.71 & 1.06 & 1.2 & 1.4 & 1.6 & 1.4 & 1.1 & 1.3 & 1.3 & 1.1 & 1.1 \\
\hline Error estándar de la media & 0.033 & 0.029 & 0.036 & 0.045 & 0.076 & 0.078 & 0.051 & 0.086 & 0.059 & 0.066 & 0.035 & 0.038 & 0.017 \\
\hline Relación calcio-fósforo & 0.30 & 0.74 & 0.86 & 0.68 & 0.68 & 0.77 & 0.71 & 0.71 & 0.69 & 0.68 & 0.69 & 0.71 & 0.75 \\
\hline
\end{tabular}

favorable, encontrándose un promedio de 0.75 , que no se encuentra lejos de la relación óptima que es de 1. Probablemente el contenido de calcio del agua de pozo (promedio de $\mathrm{mg} /$ litro) contribuye a alcanzar los requerimientos.

No se consideró necesario medir el consumo de vitamina $\mathrm{D}$ por la gran exposición de la gente a los rayos solares durante periodos prolongados y con ropa ligera, ya que la sequedad de la región dificulta la formación de nubes que interfieran con los rayos solares y estos factores hacen poco probable deficiencia de vitamina $D$. Todas las determinaciones de fosfatasa se encontraron dentro de los límites normales.

El primer renglón del cuadro 17 contiene las recomendaciones de consumo ajustadas al grupo estudiado, calculadas por el uso de los valores del National Research Council para la distribución de edades y sexos de este estudio. En el segundo renglón se observan los promedios de consumo encontrados y en el tercero el porcentaje de las recomendaciones alcanzado. Se puede apreciar que el consumo de vitamina A, tiamina, ácido ascórbico y hierro puede considerarse como muy bueno, ya que exceden a los valores recomendados. El nivel de calcio se encontraba un poco bajo pero probablemente satisfactorio. Los consumos de proteínas, especialmente consideradas desde el punto de vista cualitativo, calorías y niacina eran ligeramente bajos. Posiblemente el consumo de niacina se encontraba aun más bajo por el elevado consumo de maíz. La riboflavina es el único nutrimento que podría caracterizarse como suficientemente inadecuado para producir signos clínicos.

\section{Hallazgos físicos}

Una consideración importante en nuestra elección de esta área para un estudio de nutrición fue el conocimiento de que se trata de una de las más pobres en México. No obstante, se observaron muy pocas deficiencias nutricionales clínicas. La gente era de baja estatura y delgada pero no en extremo. Probablemente el fenómeno de posible origen nutricional que más llamó la atención fue la baja talla y el retraso en el desarrollo de los niños para su edad. Hasta qué punto es esta una característica racial o en qué medida se debe a deficiencias nutricionales, es algo que no puede aún determinarse. En la mayoría de los niños el consumo promedio de varios nutrimentos, en relación a las recomendaciones del National Research Council, fue bajo. La desnutrición en algunos niños se hacía evidente por una delgadez marcada, retardo en el crecimiento y desarrollo, palidez, etc., y no por síndromes francos tales como escorbuto, pelagra y raquitismo.

La piel de estas personas era casi siempre seca y escamosa, y frecuentemente endurecida y agrietada, especialmente en las áreas expuestas, y con incremento en las alteraciones a medida que aumentaba la edad. Existen reservas para atribuir estas alteraciones a deficiencias nutricias, ya que la región es muy seca, 
Cuadro 17

RESUMEN DE LOS CONSUMOS PROMEDIO OBSERVADOS, COMPARADOS CON LOS CONSUMOS RECOMENDADOS PARA UNA PERSONA PROMEDIO

\begin{tabular}{|c|c|c|c|c|c|c|c|c|c|}
\hline & Calorías & $\begin{array}{l}\text { Proteínas } \\
\text { (g) }\end{array}$ & $\begin{array}{l}\mathrm{Ca} \\
(\mathrm{g})\end{array}$ & $\begin{array}{l}\mathrm{Fe} \\
(\mathrm{mg})\end{array}$ & $\begin{array}{l}\text { Vitamina A } \\
\text { (U.I.) }\end{array}$ & $\begin{array}{c}\text { Tiamina } \\
\text { (mg) }\end{array}$ & $\begin{array}{l}\text { Riboflavina } \\
\qquad(\mathrm{mg})\end{array}$ & $\begin{array}{c}\text { Niacina } \\
\text { (mg) }\end{array}$ & $\begin{array}{l}\text { Acido } \\
\text { ascórbico } \\
\text { (mg) }\end{array}$ \\
\hline $\begin{array}{l}\text { Consumos recomendados por el National Research } \\
\text { Council corregidos para la distribución y sexo estudiado }\end{array}$ & 2430 & 64.0 & 0.96 & 11.4 & 4331 & 1.19 & 1.66 & 11.9 & 68.1 \\
\hline Consumo promedio observado & I 706 & 51.0 & 0.82 & 23.2 & 5498 & 1.61 & 0.69 & 9.4 & 93.3 \\
\hline Porcentaje de consumo recomendado & 70 & 80 & 85 & 203 & 127 & 135 & 42 & 79 & $|4|$ \\
\hline
\end{tabular}

soleada, con mucho polvo y viento, la gente no se baña frecuentemente, está casi siempre invadida de piojos y su ropa brinda poca protección contra dichos agentes físicos; en estas condiciones uno esperaría encontrar alteraciones en la piel. Además, se encontró que algunas alteraciones en las conjuntivas, incluyendo pinguécula, aparecían más temprano y eran más graves que en algunas otras regiones de México que hemos estudiado; sin embargo, podrían ser atribuidas a los efectos físicos del sol, viento, sequedad y polvo y no a deficiencias de vitamina A.

Los signos clínicos más comunes de probable deficiencia fueron queilosis y glositis; no obstante, se ha dudado de la especificidad de la queilosis como signo de deficiencia de riboflavina, complejo B y otra deficiencia nutricional. Fue imposible realizar un experimento terapéutico debidamente controlado, por falta de cooperación suficiente. En dos de las comunidades logramos que 13 personas con queilosis angular aguda se sometieran a tratamiento de riboflavina (5 $\mathrm{mg}$ de dosis diaria total) con regularidad razonable. Durante las primeras dos semanas se observó poca mejoría, pero finalmente, desde la tercera a la cuarta semanas cinco personas fueron curadas o mejoraron notablemente y tres presentaron mejoría moderada. Al parecer todas las personas con queilosis habrían tenido reacciones positivas si hubieran continuado sometidas al tratamiento durante un periodo suficiente. Pero este experimento no puede ser considerado como crucial, pensamos que sugiere que los casos de queilosis encontrados eran deficiencias del complejo B, y más específicamente de riboflavina. Siete de las trece personas tratadas con riboflavina o complejo B mostraron también un grado moderado de invasión corneal y en cinco permanecía aun presente al final del tratamiento.
Es interesante observar que la incidencia de queilosis entre los que consumían cantidades considerables de pulque ( $500 \mathrm{ml}$ o más diariamente) fue de $9 \%$ contra $45 \%$ en los que consumían cantidades menores o no lo consumían. Al intentar tomar en cuenta el factor edad en el análisis, resultaron grupos muy pequeños para ser estadísticamente significativos; empero los porcentajes resultantes sugieren que la vitamina B del pulque ayudó a prevenir la aparición de signos de deficiencia del complejo B, como queilosis.

La glositis de grado agudo también fue común. En este estudio las condiciones no fueron favorables para el tratamiento satisfactorio de un grupo; sin embargo, en otras regiones hemos encontrado lenguas de apariencia similar que respondieron al tratamiento con vitaminas y complejo B. Por lo expuesto, pensamos que en la mayoría de los casos las alteraciones en la lengua observadas en este estudio eran debidas a una deficiencia del complejo B. Los efectos de traumas como el consumo de grandes cantidades de chile muy picante pueden ser también importantes.

El cuadro 18 resume los hallazgos del examen realizado con una lámpara de exploración física, porque en mayor proporción se realizaron estudios en adultos que en niños, por lo que se le debe dar mayor peso a las alteraciones sufridas por los adultos al hacer el análisis de los resultados del grupo en su totalidad. No se hizo por separado el análisis de los casos agudos y los crónicos pero aproximadamente el $60 \%$ de los casos de gingivitis y el $94 \%$ de los de glositis fueron considerados como crónicos. Se puede observar que, con excepción de la vascularización corneal, la edad o factores asociados con esta resultaron causas contribuyentes a la aparición de estas alteraciones, ya que hay un aumento de su incidencia entre personas de más edad. Consecuentemente, somos escépticos del 
Cuadro 18

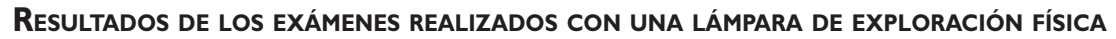

\begin{tabular}{|c|c|c|c|c|c|c|c|}
\hline \multirow[b]{2}{*}{ Edad (años) } & \multirow{2}{*}{$\begin{array}{c}\text { Corneal } \\
\text { Porcentaje } \\
\text { con } \\
\text { vascularización }\end{array}$} & \multicolumn{2}{|c|}{ Alteraciones en conjuntivas } & \multicolumn{2}{|c|}{ Gingivitis } & \multicolumn{2}{|c|}{ Glositis } \\
\hline & & $\begin{array}{l}\text { Porcentaje } \\
\text { del total }\end{array}$ & $\begin{array}{c}\text { Porcentaje } \\
\text { con alteraciones } \\
\text { marcadas }\end{array}$ & $\begin{array}{l}\text { Porcentaje } \\
\text { del total }\end{array}$ & $\begin{array}{c}\text { Porcentaje } \\
\text { con alteraciones } \\
\text { marcadas }\end{array}$ & $\begin{array}{l}\text { Porcentaje } \\
\text { del total }\end{array}$ & $\begin{array}{c}\text { Porcentaje } \\
\text { con alteraciones } \\
\text { marcadas }\end{array}$ \\
\hline $4-9$ & 30 & 75 & 6 & 62 & 6 & 65 & 12 \\
\hline $110-15$ & 46 & 77 & 15 & 69 & 13 & 78 & 26 \\
\hline 16 y más (s. masculino) & 48 & 97 & 75 & 89 & 43 & 97 & 45 \\
\hline 16 y más (s. femenino) & 36 & 97 & 77 & 85 & 49 & 96 & 57 \\
\hline Todo el grupo & 42 & 94 & 66 & 84 & 41 & 93 & 46 \\
\hline
\end{tabular}

valor de estos exámenes de exploración física, particularmente los de la córnea, conjuntiva y encías, como criterio de estado nutricio, a menos que se refuercen con otras evidencias clínicas. ${ }^{19}$

El cuadro 19 presenta la incidencia de algunos signos y síntomas clínicos, debidos posiblemente al estado nutricio. Pensamos que es poco probable que muchos de estos signos y síntomas sean debidos a deficiencias nutricias en porcentajes grandes de los casos estudiados.

Por la extrema sequedad de la región no existe la trasmisión del paludismo en estas comunidades; sin embargo, ocasionalmente algunas de las personas de las comunidades acudían a trabajar por periodos cortos a regiones irrigadas del Valle y regresaban con la enfermedad. Nos llamó mucho la atención la baja incidencia de hipertensión en estos indígenas, comparados con estadounidenses. Esto también se observó en varios grupos de mestizos que estudiamos. La incidencia de soplos cardiacos es también menor que la observada en los Estados Unidos.

La gente tenía muy buena dentadura considerando que no recibían atención dental y no tenían prácticas higiénicas. Los resultados de los exámenes dentales se presentan en el cuadro 20.*

Para uno que está acostumbrado a ver la elevada incidencia de problemas dentales en la mayor parte de los Estados Unidos, la observación de que casi el 50\% de los adultos tenía dentaduras perfectas fue asombrosa. En algunas bocas se observó la formación de gran

\footnotetext{
* Los estudios dentales se hicieron en colaboración con Félix R. Leycegui, DDS. Una descripción más detallada de los resultados de exámenes dentales en esta y otras regiones de México se darán a conocer por separado.
}

cantidad de cálculos. La incidencia de gingivitis muy evidente en el examen dental fue alta, mientras que la de piorrea fue baja.

Desde el punto de vista dietético los principales factores considerados como importantes en la formación de los dientes están cubiertos. Los consumos de vitaminas A y C, calcio y fósforo son relativamente correctos y hay suficiente exposición al sol para cubrir los requerimientos de vitamina D. Aunque la dieta es elevada en carbohidratos, debido principalmente a las tortillas, prácticamente no se consumen azúcares. No se encontró evidencia clínica de fluorosis. El examen del agua de varios de los pozos mostró 0.2 a $0.3 \mathrm{ppm}$ de fluoruro. Esta cifra está muy por debajo del séptimo considerado como adecuado para la prevención de la caries.

No fueron comunes las deficiencias nutricias clínicas. La única deficiencia evidente tanto clínicamente como a través de los registros dietéticos, fue la de riboflavina. Debido al elevado consumo de maíz, probablemente existía alguna deficiencia de niacina. El consumo de calorías y el de proteínas, desde el punto de vista cualitativo, fueron moderadamente bajos. El consumo de vitamina A, tiamina, ácido ascórbico, hierro, calcio y fósforo se encontraba dentro de los limites correctos.

Los mayores signos clínicos de deficiencia encontrados fueron queilosis angular y glositis. El crecimiento juzgado por los patrones de Estados Unidos de América, se encontraba retardado; sin embargo, es imposible evaluar adecuadamente el estado nutricional sin tomar en cuenta factores étnicos. Los dientes se encontraron en excelente estado.

Los estudios de la sangre, que incluyeron examen hematológico, determinación de proteínas, y vitaminas A y $\mathrm{C}$, revelaron valores que en general se compararon favorablemente con datos encontrados en otros estudios. 


\section{Cuadro 19}

RESULTAdOS DE EXÁMENES FísICOS, HISTORIAS CLÍNICAS Y VARIOS ESTUDIOS DE LABORATORIO*

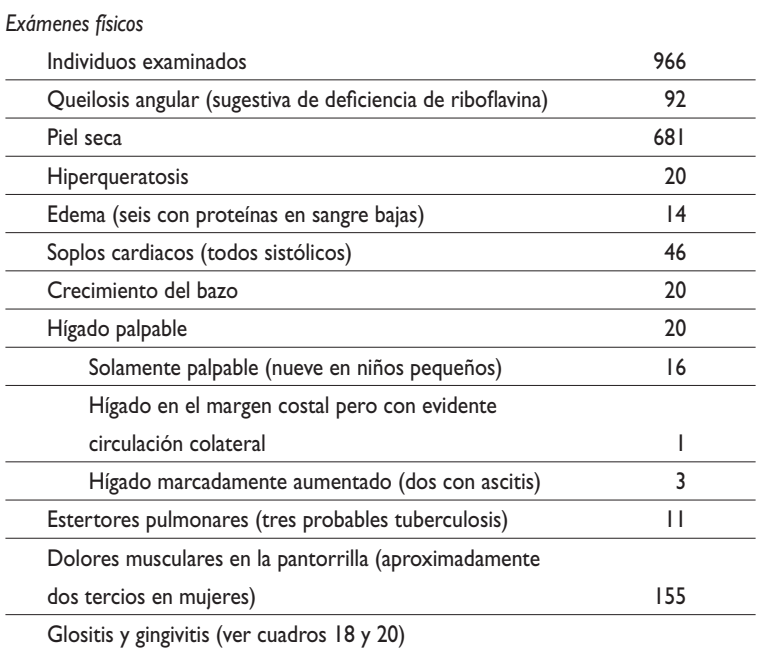

\begin{tabular}{|c|c|}
\hline \multicolumn{2}{|l|}{ Historia clínica } \\
\hline Fotofobia u ojos inflamados & 300 \\
\hline Hemeralopía & 67 \\
\hline Lengua inflamada o dolorosa & 153 \\
\hline Encías sangrantes & 126 \\
\hline Síntomas gastrointestinales & 92 \\
\hline Anorexia & 47 \\
\hline Náusea o vómitos & 37 \\
\hline Diarrea & 36 \\
\hline Parestesias, calambres o dolores musculares & 371 \\
\hline Fatiga, debilidad e irritabilidad & 184 \\
\hline Palpitaciones & 26 \\
\hline Ganancia de peso & 170 \\
\hline Pérdida de peso & 219 \\
\hline \multicolumn{2}{|l|}{ Exámenes de laboratorio } \\
\hline \multicolumn{2}{|l|}{ Serología positiva (Klein y Kahn) } \\
\hline Todo el grupo & $12 \%$ \\
\hline Adultos sexo masculino & $20 \%$ \\
\hline Muestras positivas de paludismo (todas Plasmodium vivax) & 5 \\
\hline Fosfatasa y determinaciones de fósforo (niños menores de 5 años) & 52 \\
\hline Fósforo promedio & $5.0 \mathrm{mg}$ \\
\hline Fosfatasa promedio (valor máximo de 10.4) & 5.6 unidades \\
\hline
\end{tabular}

\footnotetext{
* Los resultados de las historias clínicas y ciertos hallazgos físicos, v. gr., dolores musculares en la pantorrilla, deben evaluarse en términos del bajo nivel intelectual de la gente estudiada, la existencia de barreras de lenguaje en algunos casos y su frecuente deseo de recibir medicamentos por enfermedades reales o imaginadas. Hicimos un intento por reducir los efectos de estos factores, pero indudablemente influyeron en los resultados
}

Cuadro 20

Resultados del examen dental

\begin{tabular}{|c|c|c|c|c|}
\hline Edad (años) & $\begin{array}{c}\text { Número de personas } \\
\text { examinadas }\end{array}$ & $\begin{array}{c}\text { Porcentaje con dientes } \\
\text { perfectos }\end{array}$ & $\begin{array}{c}\text { Porcentaje de dientes } \\
\text { deteriorados }\end{array}$ & $\begin{array}{c}\text { Porcentaje de personas } \\
\text { con gingivitis }\end{array}$ \\
\hline Menos de 2 & 14 & 100 & 0 & 0 \\
\hline $2-6$ & 123 & 81 & 2.0 & 1.6 \\
\hline $7-11$ & 97 & 65 & 3.9 & 36 \\
\hline $12-15$ & 64 & 69 & 3.1. & 45 \\
\hline 16 y más (hombres) & 107 & 48 & 8.0 & 83 \\
\hline 16 y más (mujeres) & 182 & 39 & 8.7 & 85 \\
\hline
\end{tabular}

Da la impresión de que, no obstante la esterilidad y pobreza de la región, sus habitantes, a lo largo de muchos siglos, han desarrollado hábitos alimentarios y un modo de vida adaptados a ese ambiente. Cualquier intento de modificación sería un error mientras no se mejoren sus condiciones económicas y sociales y se logren condiciones realmente más favorables.

\section{Agradecimientos}

Los autores desean agradecer la cooperación y facilidades brindadas a ellos por el doctor Francisco Miranda, director del Instituto de Nutriología; el doctor Manuel B. Márquez Escobedo, director del Centro de Adiestramiento de la Escuela de Higiene y el doctor Ángel de la 
Garza Brito, director de la Escuela de Higiene. Estamos en deuda con el señor Leobardo B. Terpan, por su ayuda en ciertas fases del trabajo de campo y en los cálculos estadísticos. También agradecemos la ayuda técnica de las señoritas Mercedes Prieto López y Consuelo Sánchez Mesa en el laboratorio y la señorita Antonia Montaños, la señora Mercedes Magaña Vda. de Galindo, la señorita Ausencia Lutrillo Rojas y la señorita Ofelia Carrasco que, en varios momentos colaboraron en la obtención de las encuestas dietarias.

\section{Referencias}

I. Cravioto, R., Lockhart, E.E.,Anderson, R.K., Miranda, F.y Harris, R.S. Composition of typical mexican foods. J. Nutrition, 29:317, 1945. 2.Wintrobe, M.M. Clinical hematologr. filadelfia, Lea and Febiger, 1942, pp. 200-201.

3. Evelin, K.A. Stabilized photoelectric colorimeter wilh light filters.J. Biol. Chem., 135:707, 1940.

4. Robinson, H.W. y Hogden, CG. Biuret reaction in determination of serum proteins. J Biol Chem I35:707, 1940.

5. Kimble, M.S. Photoelectric determination of vitamin A and carotene in human plasma.J Lab \& Clin Med, 24: 1055, 1939.

6. Midlin, R.L. y Butler,A.M. Determination of ascorbic acid in plasma: a macromethod and micromethod.J Biol Chem, I22:673, 1938.

7. Bodansky,A. Phosphatase studies: determination of serum phosphatase. Factors influencing accuracy of determinations.J Biol Chem, I0I :93, 1933. 8. Wilder, Russel M. Misinterpretation and misuse of the recommended dietary allowance. Science, I0I :285, I945.

9. Robinson, W.D., Payne, G.C y Calvo, J.A. Study of the nutritional status of a population group in Mexico City. J.A. Dietet.A., 20:289, 1944. I0. Youmans, J.B., Patton, E.W.y Kern, R. Surveys of the nutrition of populations. Description of the population, general methods and procedures and the findings in respect to the energy principle (calories) in a rural population in Middle Tennessee. Parte 2.A.J.P.H., 33:58, 1943.

I I. Milam, D.F.y Anderson, R.K. Nutrition survey of an entire rural country in North Carolina. South, M.J., 37:597, 1944.

12. Youmans, I.B., Patton, E.W., Sutton, W.R., Kern, R. y Steinkamp, R. Surveys of the nutrition of populations. 2. The protein nutrition of a rural population in Middle Tennessee.A.J.P.H., 33:955, 1943.

13. Corn germ, a valuable protein food. Nutrition Review, 2:2 2 2, 1944. 14. Development of liver injury in rats on yeast protein diet. Nutrition Rev., 2: 180, 1944

15. Metocoff, J., Favour, CB., y Stare, F.J. Plasma protein and hemoglobin inlhe protein-deficient rat.A three-dimensional study. J. Clin. Investigation, 24:82, 1945

16. Wetzel, N.C. Physical fitness in terms of physique development and basal metabolism. J.A.M.A., I|6: | |87, |94|.

17. Youmans, J.B., Patton, E.W., Sutton,W.R., Kern, R. y Steinkamp, R. Surveys of the nutrition of populations. 3. The vitamin $A$ nutrition of a rural population in Middle Tennessee.A.J.P.H., 34:368, 1944.

18. Levels of carotene and vitamin A in human blood. Nutrition Rev. 3:38, 1945.

19a. Anderson, R.K.y Milam, D.F. Biomicroscopy of the eyes in evaluation of nutritional status. Conjunctival changes.J Nutrition, 30: II, 1945.

19b. J Anderson, R.K.y Milam, D.F. Biomicroscopy of the eyes in evaluation of nutritional stalUS. Corneal vascularization. J. Nutrition, 30:17,1945.

20. Melnick, D.A. Critique of values suggested as the thiamin requirement of man.J Am. Dietet.A., 20:516, 1944

21.Williams, R.D., Mason, H.L., Cusick, P.L. y Wilder, R.M. Observation on induced riboflavin requirement of man. J. Nutrition, 25:36I, 1943.

22. Milam, D.F.A nutrition survey of a small North Carolina Community. A.J.P.H., 32:406, 1942.

23. Hurtado, A., Merino, C.y Delgado, E. Influence of anoxemia on the hematopoietic activity. Arch. Int. Med., 75:284, 1945.

24. Gutiérrez Villarreal,A. El volumen corpuscular medio. Tesis, Escuela Médico Militar, Mexico, 1942.

25. Klein, H.y Palmer, C.E. Dental caries in American Indian children, Pub Health Bull., 239, US Govt. Ptg. Office, dic. 1937. 